\title{
Surface Coatings Protect against the In vitro Toxicity of Zinc Oxide Nanoparticles in Human Hepatic Stellate Cells
}

Megan J Osmond-McLeod ${ }^{1 *}$, Yalchin Oytam ${ }^{1,2}$, Ronald IW Osmond ${ }^{3}$, Fariborz Sobhanmanesh ${ }^{2}$ and Maxine J McCall ${ }^{1}$

${ }^{1}$ CSIRO Advanced Materials TCP (Nanosafety), and CSIRO Food and Nutrition Flagship, North Ryde NSW 1670, Australia

${ }^{2}$ CSIRO Genomics and Cellular Sciences, Transformational Biology CP, North Ryde NSW 1670, Australia

${ }^{3} T$ TR Biosciences, Thebarton SA 5031, Australia

\begin{abstract}
Coatings applied to the surfaces of zinc oxide $(\mathrm{ZnO})$ nanoparticles have been shown to decrease the capacity of uncoated nanoparticles to generate free radicals, as well as to reduce their solubility, and may be utilized in safetyby-design approaches to decrease $\mathrm{ZnO}$ nanoparticle toxicity. The liver is a target organ for $\mathrm{ZnO}$ nanoparticles, or ionic zinc released from $\mathrm{ZnO}$ nanoparticles, whether the route of entry is by dermal absorption, ingestion, injection or inhalation. Liver injury and fibrosis have been demonstrated in vivo in response to $\mathrm{ZnO}$ nanoparticle treatment, and cell injury has also been shown in vitro using immortalized hepatocyte cell lines. Despite their activation being a critical step for liver fibrosis, however, the response of human hepatic stellate cells (hHSCs) to ZnO nanoparticles has not yet been reported. Here, hHSCs were treated with four types of commercially-available $\mathrm{ZnO}$ nanoparticles suspended in cell culture medium. Two types were uncoated nanoparticles of different sizes, and the other two types with similar particle size carried different surface coatings. Cells were also treated with pre-dissolved $\mathrm{ZnSO}_{4}$ to provide a comparison of the cellular responses induced by ionic zinc. A systems biology approach was utilized whereby the activation of cell signaling pathways, changes in the transcriptome, and alterations in cellular function were assessed over a $24 \mathrm{~h}$ period. Treatment with both types of uncoated $\mathrm{ZnO}$ nanoparticles mobilized pathways and responses centered on cellular stress, survival, and apoptosis. Both surface coatings conferred almost complete protection against $\mathrm{ZnO}$ nanoparticle-induced cytotoxicity. Ionic zinc had little effect on these cells indicating that toxicity is mainly induced by the nanoparticles. The results presented here support the use of surface coatings in commercial applications of $\mathrm{ZnO}$ nanoparticles where there is human exposure.
\end{abstract}

Keywords: Zinc oxide nanoparticle; Human hepatic stellate; Nanoparticle coating; Gene expression; Cell-signaling

\section{Introduction}

The unique catalytic, UV-absorbing, electronic, and optical properties of zinc oxide $(\mathrm{ZnO})$ nanoparticles have been exploited throughout a range of technological innovations, some of which may result in direct consumer contact. For example, their inclusion in personal-care products, biomedical and antimicrobial applications, and food and agricultural technologies [1-5], may result in nanoparticle entry, both intended and unintended, into the human body. Therefore, the biodistribution, fate, and impact of $\mathrm{ZnO}$ nanoparticles in vivo, as well as their impact on various cell populations in vitro, are important to assess. In vitro studies have shown that $\mathrm{ZnO}$ nanoparticles can exert oxidative, genotoxic, and cytotoxic effects across a range of cell types [6]. Although other mechanisms may contribute [7-9], the predominant cause of $\mathrm{ZnO}$ nanoparticle toxicity has been ascribed to the release of ionic zinc $[10,11]$. The presence of a stable surface coating has previously been shown to exert a protective effect on $\mathrm{ZnO}$ nanoparticle cytotoxicity in primary human olfactory cells [12], potentially via more than one mechanism, including a reduction in free radical generation $[13,14]$, retarding, or preventing, particle dissolution [15], or rendering the particles less available for cellular uptake.

The liver has been shown to be a target organ for the accumulation and/or biological impact of $\mathrm{ZnO}$ nanoparticles, or $\mathrm{Zn}^{2+}$ released from $\mathrm{ZnO}$ nanoparticles. This is so, regardless of whether the route of entry is by dermal absorption [16], ingestion [17-21], injection [17], or inhalation [22]. Hepatocytes are the predominant cell type in the liver, contributing approximately $80 \%$ to its mass, as well as much of its function, and their response to in vitro treatment with $\mathrm{ZnO}$ nanoparticles has been investigated elsewhere using immortalised cell lines [9,23-28]. A critical stage in the fibrotic response of the liver to injury, however, is the activation of hepatic stellate cells $[29,30]$, which also function in retinoid storage and transport, immunoregulation, secretion of growth factors, lipoproteins and cytokines, and metabolism, and detoxification [30]. Liver injury and fibrosis have been reported outcomes in vivo in rodents following ingestion [18,20,21] and inhalation [22] of $\mathrm{ZnO}$ nanoparticles, suggesting that the response of hepatic stellate cells to $\mathrm{ZnO}$ nanoparticles is highly relevant.

Here, we examined the response of primary human hepatic stellate cells (hHSCs) to treatment with four types of $\mathrm{ZnO}$ nanoparticles that are available commercially, and are used in personal care products, such as sunscreens, as well as zinc sulphate $\left(\mathrm{ZnSO}_{4}\right)$, which was included as a source of ionic zinc. Two types of $\mathrm{ZnO}$ nanoparticles were coated, and two were uncoated. A systems biology approach incorporating assessments of cell function and viability, the activations of cell signalling pathways, and whole genome transcriptional profiling, was utilized. The profiles of cells treated with either of the two types of uncoated $\mathrm{ZnO}$ nanoparticles were consistent with an initial activation of cellular stress and protection responses, followed by disregulation of the transcriptome, and induction of apoptosis. The presence of stable surface coatings, on the other hand, mitigated the cytotoxicity of $\mathrm{ZnO}$

*Corresponding author: Megan Osmond McLeod, CSIRO Food and Nutrition Flagship, PO Box 52, North Ryde, NSW, 1670, Australia, Tel: 612-94905035; Fax: 612-94905010; E-mail: megan.osmond@csiro.au

Received August 26, 2014; Accepted September 25, 2014; Published October 05, 2014

Citation: Osmond-McLeod MJ, Oytam Y, Osmond RIW, Sobhanmanesh F, McCal MJ (2014) Surface Coatings Protect against the In vitro Toxicity of Zinc Oxide Nanoparticles in Human Hepatic Stellate Cells. J Nanomed Nanotechnol 5: 232 doi: 10.4172/2157-7439.1000232

Copyright: (C) 2014 Osmond-McLeod MJ, et al. This is an open-access article distributed under the terms of the Creative Commons Attribution License, which permits unrestricted use, distribution, and reproduction in any medium, provided the original author and source are credited. 
nanoparticles, rendering them relatively benign. Ionic zinc was not found to elicit a similar stress response to that induced by uncoated $\mathrm{ZnO}$ nanoparticles in hHSCs under these conditions.

\section{Materials and Methods}

\section{Treatments used in this study}

Cells were treated with one of four types of $\mathrm{ZnO}$ nanoparticles, $\mathrm{ZnSO}_{4}$ (Sigma, Cat\# 96495), or were untreated. Two types of the $\mathrm{ZnO}$ nanoparticles were uncoated [Z-COTE (BASF, Batch\# EHDA3001), and Nanosun P99/30 (Micronisers, Batch\# 4051)]; and two were coated [Z-COTE HP1 (BASF, Batch\# CNHE0602), coated with triethoxycaprylylsilane, and Z-COTE MAX (BASF, Batch\# FCHE1301), coated with a dimethoxydiphenylsilane/triethoxycaprylylsilane crosspolymer].

\section{Physicochemical characterization of nanoparticles}

The methods used for extensive physicochemical characterization of the nanoparticles as powders, or as dispersions in $\mathrm{H}_{2} \mathrm{O}$ or saline, have been described elsewhere [12]. Briefly, primary particle size, size distribution, and shape were assessed by transmission electron microscopy(TEM) using a Tecnai 12 TEM(FEI, Eindhoven, Netherlands) operating at $120 \mathrm{kV}$ under a variety of magnifications. Specific surface areas were determined using the Brunauer-Emmett-Teller (BET) gasadsorption technique [31]. The $\mathrm{ZnO}$ nanoparticles were determined to be free of endotoxin using a QLC-1000 Chromogenic LAL kit (Lonza). Levels of peroxynitrile and superoxide radicals generated by the particles dispersed in saline solution were measured under light and dark conditions using electron paramagnetic resonance (EPR), with TEMPONE-H (Enzo Life Sciences, Australia) as the spin trap. Dynamic light scattering (DLS) and zeta potential measurements were taken in $\mathrm{H}_{2} \mathrm{O}$ at $0 \mathrm{~h}$ using a Zetasizer Nano Series (Malvern Instruments, ATA Scientific, Australia), to assess average hydrodynamic particle size and surface charge, respectively. In addition, hydrodynamic particle size distributions in $\mathrm{H}_{2} \mathrm{O}$ at $0 \mathrm{~h}$ were measured by differential centrifugal sedimentation (DCS) (CPS DC24000 UHR Disc Centrifuge, LPS Instruments, Inc.).

For this study, dispersions of nanoparticles $(30 \mu \mathrm{g} / \mathrm{mL})$ in supplemented cell culture medium (HM-5201, ScienCell ${ }^{\mathrm{TM}}$ Research Laboratories, USA) were also characterized for particle size and surface charge. DLS, zeta potential, and DCS measurements were taken at 0 , 2, 6 and $24 \mathrm{~h}$. A calibrated pH meter (Waterproof pHTestr2, Oakton Instruments) was used to measure the $\mathrm{pH}$ of the cell-culture medium containing nanoparticles, $\mathrm{ZnSO}_{4}$, or no treatments, at $0,2,6$ and $24 \mathrm{~h}$.

\section{Cell cultures}

Primary human hepatic stellate cells at passage 5 (p5) were propagated as adherent monolayers in complete hepatocyte medium (HM-5201, ScienCell ${ }^{\mathrm{TM}}$ Research Laboratories). Cells were propagated from an original culture of primary human hepatocyte cells (HH-5200, ScienCell ${ }^{\mathrm{TM}}$ Research Laboratories), and the hepatic stellate cell type was confirmed by morphology. All incubations were performed at $37^{\circ} \mathrm{C}, 10 \% \mathrm{CO}_{2}$.

\section{Preparation of experimental suspensions}

In vitro experiments were performed as traditional suspension exposures. $\mathrm{ZnO}$ nanoparticle powders, or $\mathrm{ZnSO}_{4}$, were weighed into clean, sterile $50 \mathrm{~mL}$ Falcon tubes, and cell-culture medium was added to make stock suspensions $(1 \mathrm{mg} / \mathrm{mL})$. The suspensions were briefly vortexed, then bath sonicated for $10 \mathrm{~min}$ to disperse the nanoparticles. Appropriate test concentrations were prepared by diluting the stock suspension with medium, followed by bath sonication for a further 10 min just prior to use.

\section{Selection of experimental test concentration}

Cells were seeded $(10,000$ cells/well) into clear 96 -well plates and incubated overnight. Medium was removed and replaced in quadruplicate wells with medium containing $10,20,30,40,50,60$, 70 , or $80 \mu \mathrm{g} / \mathrm{mL}$ nanoparticles, medium containing no nanoparticles (negative control), or medium containing 5\% dimethylsulfoxide (DMSO) (positive control), and incubated. Metabolic activity was measured at $24 \mathrm{~h}$ using the MTS assay $(20 \mu \mathrm{L}$; CellTiter Aqueous MTS assay, Promega), with absorbance recorded using a SoftMax Pro5 microplate reader (Molecular Devices, USA). Signal values from wells containing medium alone, or from matched concentrations of nanoparticles incubated and assayed in the absence of cells, were used to correct for background in experimental wells. A loss of cell viability was inferred from a decrease in metabolic activity in treated cells compared to untreated cells.

\section{Cell signaling assays}

The AlphaScreen SureFire platform (PerkinElmer) was used to measure the phosphorylation ( $p$ ) of key cell signalling proteins representing five canonical signalling pathways. The specific proteins examined were NFkB p65 (p-Ser536), representing the NFkB pathway, Chk1 (p-Ser), and Chk2 (p-Ser45), representing the ATM/ATR pathway, p70 S6K (p-Thr229), representing the mTOR pathway, Akt (p-Ser473) and $\mathrm{BAD}$ (p-Ser112), representing the Akt pathway, and MEK1 (p-Thr217/Tyr221), ERK (p-Thr202/Tyr204), p38 (p-Thr185/Tyr187), c-JUN (p-Ser63/Ser73), and JNK (p-Thr185/Tyr187), representing the MAPK pathwaysMAPK pathwayss. Control agonists for JNK and NFkB (20 ng/mL TNFa), Chk1 (10 $\mu$ M doxorubicin), and Chk2 (100 $\mathrm{nM}$ hydroxyurea) were used to treat cells for 15,90 , and $120 \mathrm{~min}$, respectively, to determine whether these proteins were phosphorylated at detectable levels. Cells at p5 were seeded (80,000 cells/well) into 12-well plates and cultured overnight. Medium was removed and replaced with medium containing $30 \mu \mathrm{g} / \mathrm{mL}$ nanoparticles, $30 \mu \mathrm{g} / \mathrm{mL}$ dissolved $\mathrm{ZnSO}_{4}$, or medium containing no treatment, for $0.5,1,2,4,6$, 8,12 , and $24 \mathrm{~h}$. Four replicate wells were used for each treatment. At the appropriate time-points, treatments were removed from the wells, and the cells were lysed with $500 \mathrm{~mL} 1 \mathrm{X}$ AlphaScreen SureFire Lysis buffer, and the lysates were frozen at $-80^{\circ} \mathrm{C}$ until further analysis. An Envision multilabel plate reader (PerkinElmer) was used to measure well signals, using standard Alpha settings.

\section{Cell stress and viability assays}

A number of plate-based assays were used to assess cellular stress and function in response to nanoparticle exposure as previously described [12], with the following modifications: cells at $\mathrm{p} 5$ were seeded (10,000 cells/well) into 96-well plates and incubated overnight, after which medium was removed and replaced with medium containing $30 \mu \mathrm{g} / \mathrm{mL}$ nanoparticles, $30 \mu \mathrm{g} / \mathrm{mL} \mathrm{ZnSO}_{4}$, or medium containing no treatment, and incubated for 6 or $24 \mathrm{~h}$. Three to four replicate wells for each treatment were used for each assay. Signal background was determined as described above.

The following cellular responses were assessed: $\mathrm{NAD}(\mathrm{P})$ $\mathrm{H}$-dependent dehydrogenase activity (CellTiter $96^{\circ} \mathrm{AQ}_{\text {ueous }}$ One Solution proliferation assay, Promega), redox enzyme activity (CellTitre-Blue ${ }^{\mathrm{TM}}$ 
Citation: Osmond-McLeod MJ, Oytam Y, Osmond RIW, Sobhanmanesh F, McCall MJ (2014) Surface Coatings Protect against the In vitro Toxicity of Zinc Oxide Nanoparticles in Human Hepatic Stellate Cells. J Nanomed Nanotechnol 5: 232. doi: 10.4172/2157-7439.1000232

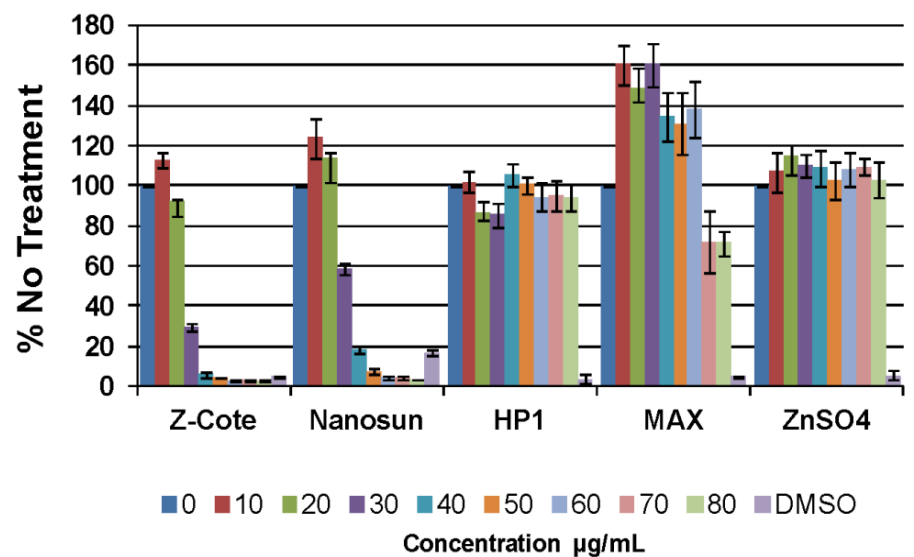

Figure 1: Metabolic activity (measured by the MTS assay) in primary human liver stellate cells exposed to four types of ZnO nanoparticle or dissolved $\mathrm{ZnSO}_{4}$ at concentrations of $\mathbf{0 - 8 0} \mathbf{\mu g} / \mathrm{mL}$. The signals at $24 \mathrm{~h}$ from cells, treated in quadruplicate for each concentration, were averaged and expressed as a percentage of signals from time-matched untreated cells set as $100 \%$. DMSO (5\%) was used as a positive control for the assay.

\begin{tabular}{|c|c|c|c|c|c|}
\hline & Z-COTE & & Namstm & HP1 & NIAX \\
\hline & Coating & None & None & Triethoxycaprylylsilane & $\begin{array}{l}\text { Dimethoxydiphenylsilane/ } \\
\text { triehoxycaprylyisilane crosspolymer }\end{array}$ \\
\hline \multirow{4}{*}{ Powder" } & Batch raimber & EHDA3001 & 4051 & CNHE0602 & FCHE1301 \\
\hline & \multirow{2}{*}{$\begin{array}{l}\text { Primary particle size (TEM, nm, \# measurements } \\
\text { in parenthis }\end{array}$} & $\begin{array}{l}\text { Width: } 44 \pm 2 \\
\quad(260)\end{array}$ & $\begin{array}{c}\text { Diameter: } 25 \pm 1 \\
(238)\end{array}$ & Width: $28 \pm 2(201)$ & Width: $36 \pm 2(300)$ \\
\hline & & $\begin{array}{l}\text { Length: } 73 \pm 4 \\
\quad(142)\end{array}$ & & Length: $96 \pm 6(93)$ & Length: $95 \pm 5$ (94) \\
\hline & Specific surface area $\left(B E T, \mathrm{~m}^{2} / \mathrm{g}\right)$ & $13 \pm 2$ & $30 \pm 3$ & $14.9 \pm 0.5$ & $12 \pm 1$ \\
\hline \multirow{6}{*}{$\ln \mathrm{H}_{2} \mathrm{O}^{\#}$} & \multirow{2}{*}{$\begin{array}{l}\text { Superoxide radical generation (\% negative } \\
\text { control) }\end{array}$} & Dark: $800 \pm 300^{*}$ & Dark: $280 \pm 80$ & Dark: $220 \pm 40$ & Dark: $170 \pm 50$ \\
\hline & & $\begin{array}{c}\text { Light: } 12,000 \pm \\
3,000^{*}\end{array}$ & Light: $2,000 \pm 400$ & Light: $4,000 \pm 700$ & Light: $4,000 \pm 300$ \\
\hline & Endotoxin & $\mathrm{BD}$ & $\mathrm{BD}$ & $\mathrm{BD}$ & $\mathrm{BD}$ \\
\hline & $\begin{array}{l}\text { Hydrodynamic particle size (DLS, nm, PDI in } \\
\text { parenthesis) }\end{array}$ & 0-time: $410(0.3)$ & 0-time: $600(0.6)$ & 0 -time: $240(0.3)$ & 0-time: broad (1) \\
\hline & Zeta potential $(\mathrm{mV})$ & 0-time: 27 & 0-time: 9 & 0-time: -10 & 0 -time: -7 \\
\hline & Altered $\mathrm{pH}$ (relative to $\mathrm{H}_{2} \mathrm{O}$ only) & 0-time: -0.1 & 0-time: 0.0 & 0-time: -0.1 & 0-time: -0.1 \\
\hline \multirow{13}{*}{$\begin{array}{l}\text { In complete } \\
\text { cell culture } \\
\text { medium } \\
(\mathrm{HM}-5201)\end{array}$} & \multirow{4}{*}{$\begin{array}{l}\text { Hydrodynamic particle size (DLS, nm, PDI in } \\
\text { parenthesis) }\end{array}$} & 0-time: $260(0.3)$ & 0-time: $25(0.7)$ & 0-time: $300(0.6)$ & 0-time: $90(0.2)$ \\
\hline & & 2h: $100(0.8)$ & 2h: $45(0.8)$ & 2h: $230(0.4)$ & 2h: $35(0.7)$ \\
\hline & & $6 h: 260(0.3)$ & $6 h: 180(0.2)$ & $6 h: 70(0.7)$ & $6 h: 340(0.4)$ \\
\hline & & 24h: $90(0.2)$ & 24h: $125(0.3)$ & 24h: $110(0.2)$ & 24h: $360(0.5)$ \\
\hline & Particle size distribution (DCS, nm) & 0-time: $90-500$ & 0-time: ND & 0-time: $20-900+$ & 0-time: $400-900+$ \\
\hline & \multirow{4}{*}{ Zeta potential (mV) } & 0-time: 8 & 0-time: 7 & 0-time: -10 & 0-time: -6 \\
\hline & & $2 \mathrm{~h}:-7$ & 2h: -7 & 2h: -7 & 2h: -6 \\
\hline & & $6 h:-7$ & $6 h:-6$ & $6 h:-7$ & $6 h:-6$ \\
\hline & & 24h: -6 & 24h: -7 & 24h: -7 & 24h: -6 \\
\hline & \multirow{4}{*}{ Altered $\mathrm{pH}$ over $24 \mathrm{~h}$ (relative to media only) } & 0-time: 0.0 & 0-time: 0.0 & 0-time: 0.0 & 0-time: 0.0 \\
\hline & & 2h: 0.0 & 2h: 0.0 & 2h: 0.0 & 2h: -0.2 \\
\hline & & 6h: 0.0 & 6h: 0.0 & 6h: 0.0 & $6 h:+0.1$ \\
\hline & & $24 h:-0.1$ & 24h: 0.0 & 24h: 0.0 & 24h: 0.0 \\
\hline
\end{tabular}

*statistically significant compared to negative control (saline only).

The physical and chemical properties of the four types of $\mathrm{ZnO}$ nanoparticles were measured as dry powders or as dispersions in either water or cell-culture medium. Polydispersity indices (PDI) are given in parentheses for measurements of hydrodynamic diameters of particles or agglomerates by DLS. BD below detection; ND not detected; "As first reported in Osmond-McLeod et al. [12].

Table 1: Physical and chemical characteristics of the four types of $\mathrm{ZnO}$ nanoparticles.

cell viability assay, Promega), ATP levels (CellTiterGlo ${ }^{\mathrm{TM}}$ luminescent cell viability assay), lactate dehydrogenase (LDH) activity (CytoTox-ONE homogenous membrane integrity assay, Promega), total glutathione (GSH) (GSH-Glo glutathione assay, Promega), chymotrypsin-like and caspase-like proteasome activities (Proteasome-Glo cell-based assays, Promega), and caspase 3-7 activity (Apo-ONE homogenous caspase-3/7 assay, Promega). Absorbance/luminescent/fluorescent signals in wells were measured using a SoftMax Pro5 microplate reader (Molecular Devices, USA).

\section{Statistical analyses for cell viability and cell signalling assays}

Time-course responses for cell viability and cell signalling assays were analyzed using GraphPad Prism 5.01 (GraphPad Software, USA). Treatment-related differences over time were assessed for statistical 
significance by 2-way ANOVA with Bonferroni's multiple comparisons test, where statistical significance was set at $p<0.05$.

\section{Whole genome transcriptional profiling by microarray}

Cells at p5 were seeded (120,000 cells/well) into 6-well plates and cultured overnight. Medium was removed and replaced for $24 \mathrm{~h}$ with medium containing $30 \mu \mathrm{g} / \mathrm{mL}$ nanoparticles, $30 \mu \mathrm{g} / \mathrm{mL} \mathrm{ZnSO}_{4}$, or medium containing no treatment. Two replicate wells were used for each treatment. RNA was isolated and assessed for integrity as previously described [12]. A total of 12 samples were prepared as one batch for microarray analysis using the Affymetrix GeneChip Human Genome U133 Plus 2 and GeneChip 3' IVT PLUS Reagent kits (both from Millennium Science, Australia) containing arrays and reagents, and following manufacturer's instructions. The microchips were prepared for hybridisation and scanning using an Affymetrix GeneChip ${ }^{\oplus}$ Hybridisation, Wash and Stain Kit (Millennium Science), hybridised $\left(16 \mathrm{~h}, 45^{\circ} \mathrm{C}, 60 \mathrm{rpm}\right.$ in an Affymetrix 640 GeneChip $^{\circ}$ Hybridization Oven), and then washed (Affymetrix GeneChip Fluidics Station 450) and scanned (Affymetrix 7G GeneChip Scanner). Data from all microarrays passed the associated quality control procedures recommended by Affymetrix.

The gene expression data were normalized by applying the robust multi-array average (RMA) algorithm using Matlab 7.7.0 (The Mathworks Inc., Natick, MA, USA). For each treatment, differentially expressed genes were identified via paired comparisons with the control group followed by correction for multiple tests as previously described [12], but with a more stringent false discovery rate (FDR) of 5\%, which was applied here in order to increase confidence in datasets that were generated from replicate microarrays. Final datasets were analyzed using the Ingenuity Pathways Analysis (IPA, Ingenuity ${ }^{\infty}$ System, www. ingenuity.com)

Microarray data are freely available on the GEO Archive (http:// www.ncbi.nlm.nih.gov/geo/) under accession number GSE60159.

\section{Results and Discussion}

To examine whether the presence of surface coatings could protect cells against $\mathrm{ZnO}$ nanoparticle cytotoxicity, primary human liver stellate cells were treated with four types of $\mathrm{ZnO}$ nanoparticles - two with surface coatings, and two uncoated. Cells were also treated with pre-dissolved $\mathrm{ZnSO}_{4}$, which was included to provide a comparison of cellular responses to ionic zinc. The test concentration selected for these experiments $(30 \mu \mathrm{g} / \mathrm{mL})$ had elicited a range of treatment-dependent differences in cell viability in an initial $24 \mathrm{~h}$ concentration-response assay (Figure 1), and was therefore anticipated to be sufficient to induce a measurable response across a range of earlier time-points up to $24 \mathrm{~h}$. A systems biology approach was taken whereby the cellular responses to treatment were assessed using a variety of cell-based stress and viability assays (measuring markers for antioxidant capacity, proteasome activity, metabolic activity, membrane integrity, and apoptosis), cell signalling assays (representing the NFkB, ATM/ATR, mTOR, AKT, and MAPK signalling pathways), and whole genome transcriptional profiling. In summary, Z-Cote and Nanosun, both uncoated but with primary particles of different sizes, clearly moderated the signalling of several cellular stress signalling pathways over a period of 4-6 h, induced a loss of cellular viability and antioxidant defences at $6 \mathrm{~h}$ and $24 \mathrm{~h}$, and strongly perturbed the transcriptional profile at $24 \mathrm{~h}$, with these effects showing little dependence on particle size. In contrast, treatment with the two coated nanoparticles, MAX and $\mathrm{HP1}$, or ionic $\mathrm{Zn}$ from $\mathrm{ZnSO}_{4}$, had little to no effect on these cells.
The powders of $\mathrm{ZnO}$ nanoparticles used in these experiments have previously been characterised and described in detail [12], and their properties are summarised here in Table 1. Briefly, highlevel magnification by TEM showed the three powders provided by BASF (Z-COTE, HP1, and MAX) to consist of a heterogeneous mix of rectangular-shaped particles (Figure 2). Interestingly, given the uncoated Z-COTE is the base particle, the coated particles, HP1 and MAX, on average are both longer and narrower giving them larger aspect ratios (length/width) than Z-COTE [HP1, mean length $96 \mathrm{~nm}$, mean width $28 \mathrm{~nm}$, aspect ratio 3.4; MAX, length $95 \mathrm{~nm}$, width $36 \mathrm{~nm}$, aspect ratio 2.6; ZCOTE, length $73 \mathrm{~nm}$, width $44 \mathrm{~nm}$, aspect ratio 1.7]. Nanosun, supplied by Micronisers, comprised smaller, homogenous spherical particles with an average diameter of $25 \mathrm{~nm}$. Consistent with their smaller size relative to the BASF particles, the specific surface area of the Nanosun particles $\left(30 \mathrm{~m}^{2} / \mathrm{g}\right)$ was more than double those of Z-COTE, $\operatorname{HP} 1$ and $\operatorname{MAX}\left(13,14.9\right.$, and $12 \mathrm{~m}^{2} / \mathrm{g}$, respectively).

DLS data are frequently reported and for this reason we include them here, but note that measurements by DLS are not suitable for this system, as evidenced by the large PDI values (Table 1 ). In water and in supplemented cell culture medium (HM-5201), all particles formed agglomerates with apparent $\mathrm{z}$-average hydrodynamic diameters greater than their primary particle size (Table 1 ). The particle size distribution in cell culture medium, as determined by DCS, was quite broad for all particle types, suggesting that a variety of agglomerate sizes were present following dispersion. Consequently, the cells were likely to have encountered a heterogeneous mix of suspended particles and agglomerates of particles in the culture treatments used here.

The surface charges for the uncoated Z-COTE and Nanosun changed from positive in $\mathrm{H}_{2} \mathrm{O}$ to negative in the supplemented cell culture medium (Table 1), suggesting that these particles became coated with negatively-charged components from the medium, most likely albumin which carries an overall negative charge at neutral $\mathrm{pH}$ [32]. The coated nanoparticles, HP1 and MAX, carried a negative surface charge in both $\mathrm{H}_{2} \mathrm{O}$ and cell culture medium. Medium $\mathrm{pH}$ did not substantially alter following $24 \mathrm{~h}$ cell-free incubation with any of the treatments, suggesting that cellular responses were not due to treatment-driven alterations in media $\mathrm{pH}$.

All four types of particles generated higher levels of superoxide radicals in the light compared to the dark (Table 1), with Z-COTE generating the highest levels in both the light and dark (Table 1).

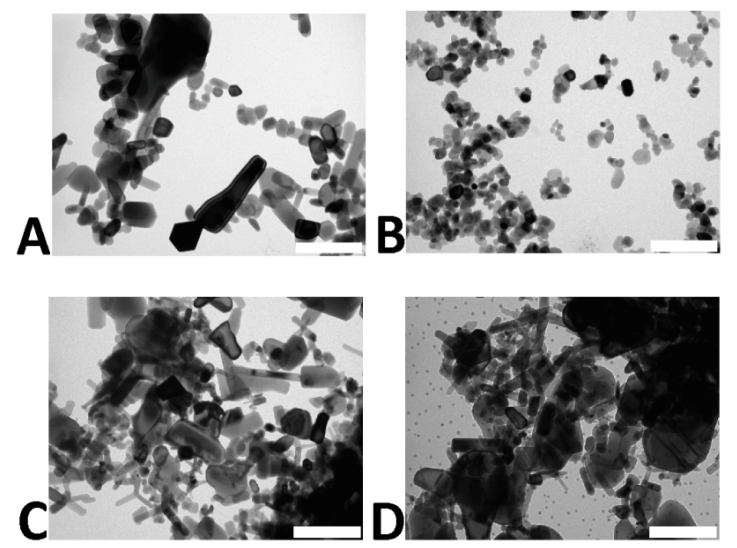

Figure 2: TEM images showing the morphologies of the $\mathrm{ZnO}$ nanoparticles used in this study. Scale bar for images A (Z-COTE), C (HP1), and D (MAX) are $200 \mathrm{~nm}$. Scale bar for image $B$ (Nanosun) is $500 \mathrm{~nm}$. 
Citation: Osmond-McLeod MJ, Oytam Y, Osmond RIW, Sobhanmanesh F, McCall MJ (2014) Surface Coatings Protect against the In vitro Toxicity of Zinc Oxide Nanoparticles in Human Hepatic Stellate Cells. J Nanomed Nanotechnol 5: 232. doi: 10.4172/2157-7439.1000232

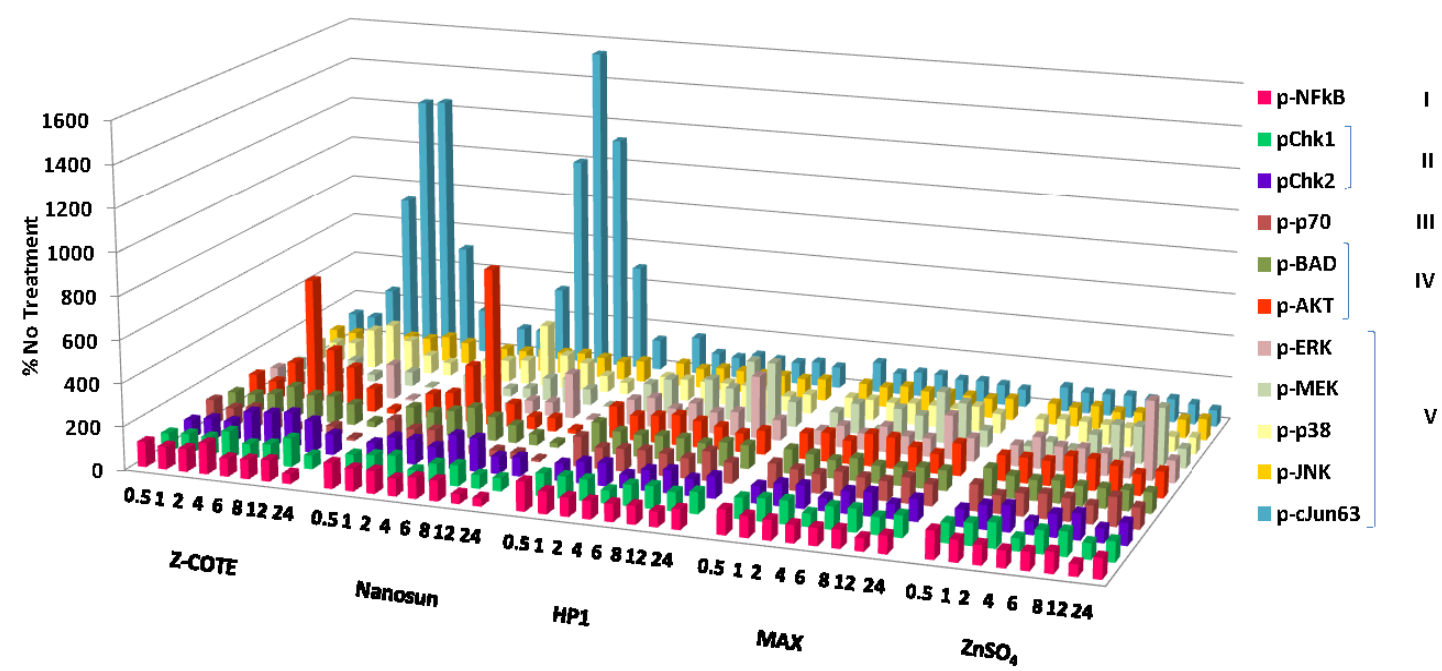

Figure 3: Phosphorylation of selected key proteins from five major cell-signalling pathways in primary human liver stellate cells treated with ZnO nanoparticles or dissolved $\mathrm{ZnSO}_{4}$, at $30 \mu \mathrm{g} / \mathrm{mL}$. Cells were treated in quadruplicate with $\mathrm{ZnO}$ nanoparticles, or $\mathrm{ZnSO}_{4}$, for each treatment time-point $(0.5,1,2$, $4,6,8,12$ and $24 \mathrm{~h}$ ). Levels of protein phosphorylation were averaged, and expressed as the percentage of phosphorylation of the same protein in untreated cells set as $100 \%$. The five cell-signalling pathways are: I NFKB (pro-inflammatory signaling); II ATM/ATR (DNA damage signalling); III mTOR (cell metabolism, growth, survival, and proliferation signalling); IV AKT (cell survival, proliferation, and apoptosis signalling); V MAPK (cell growth, survival, and differentiation signalling). The data used to generate this figure, and associated standard errors of means and statistical significance, are supplied separately in Supplementary Table 1.

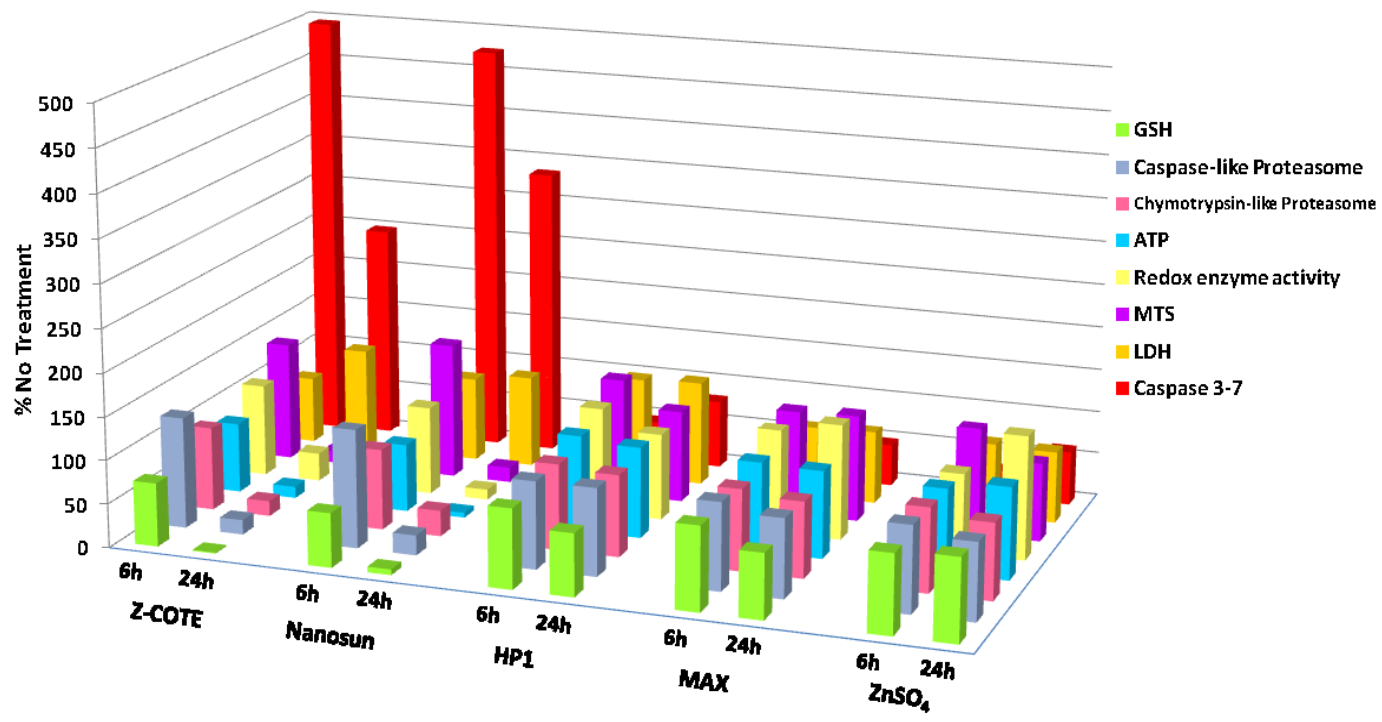

Figure 4: Changes in various cellular functions in primary human liver stellate cells treated with $\mathrm{ZnO}$ nanoparticles or dissolved $\mathrm{ZnSO}{ }_{4}$, at $30 \mathrm{\mu g} / \mathrm{mL}$ Cells were treated in triplicate or quadruplicate with $\mathrm{ZnO}$ nanoparticles, or $\mathrm{ZnSO}_{4}$, for each treatment time-point (6 and $\left.24 \mathrm{~h}\right)$. Signal levels representing different cell functions were averaged, and are expressed here as the percentage of untreated cells set as $100 \%$. Data used to generate this figure, and associated standard errors of means and statistical significance, are supplied separately in Supplementary Table 2.

Results from the cell-signalling assays are presented in Figure 3 and Supplementary Table S1, and those from the cell functional assays are shown in Figure 4 and Supplementary Table S2. Due to the large number of genes whose activity was perturbed by treatment (Figure 5), transcript levels for individual genes are not listed, but a subset is discussed in the context of other results. The levels of phosphorylated c-JUN and, to a lesser extent, $\mathrm{p} 38$ proteins were clearly increased in cells treated with Z-COTE and Nanosun compared to untreated cells (Figure 3, Supplementary Table S1). The phosphorylation of these proteins, along with JNK, are key to mediating many cellular responses associated with a variety of stresses [33-35]. In particular, the phosphorylation and activation of these stress pathways has been demonstrated to initiate stress-induced cell death in many studies, through apoptotic or senescence mechanisms [33-36] (and here, for Z-COTE and Nanosun, is consistent with the spikes in caspase 3-7 activity at $6 \mathrm{~h}$ and $24 \mathrm{~h}$ and caspase-like proteinase activity at $6 \mathrm{~h}$ (Figure 4, Supplementary Table S2). However, substantial modulation of JNK phosphorylation was not observed (Figure 3). Subsequent treatment with a control agonist (TNFa) had no measurable effect (data not shown), indicating that JNK may have been expressed at concentrations below the detection level of 


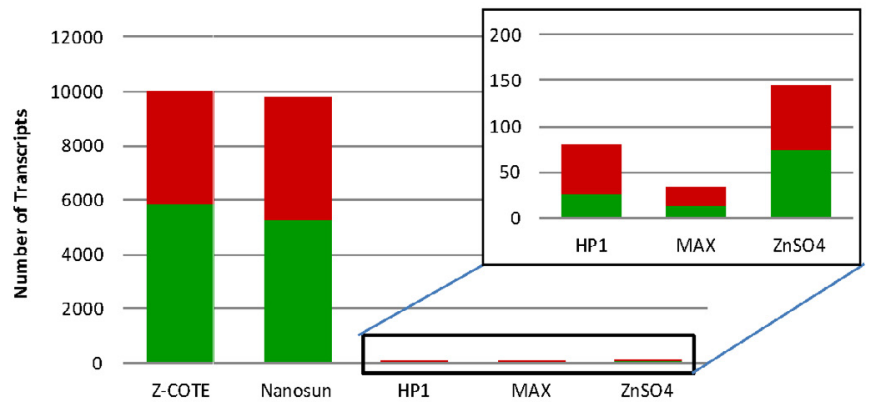

Treated > untreated
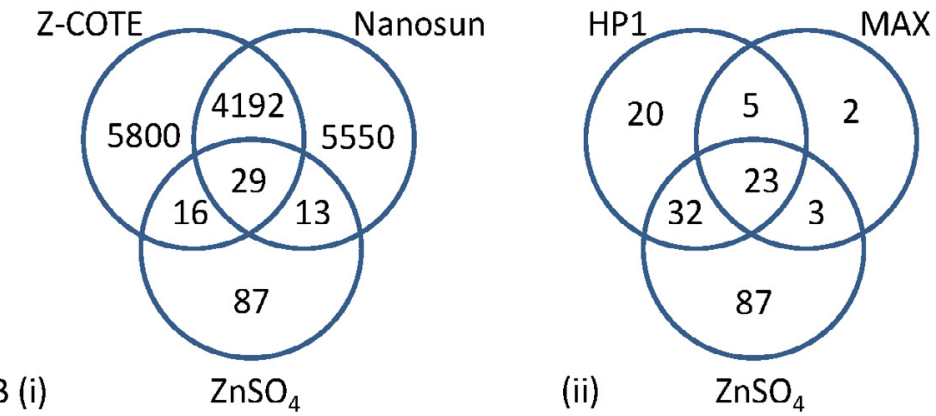

Figure 5: Differential transcript activity in primary human liver stellate cells treated with $\mathrm{ZnO}$ nanoparticles or dissolved $\mathrm{ZnSO}{ }_{4}$, at $30 \mu \mathrm{g} / \mathrm{mL}$. Cells were treated in duplicate with $\mathrm{ZnO}$ nanoparticles or $\mathrm{ZnSO}_{4}$ for $24 \mathrm{~h}$. A. Totals of differentially-expressed transcripts for each treatment grouped according to whether they were up-regulated (red) or down-regulated (green) compared to untreated cells. B. VENN diagrams showing whether differentially-expressed transcripts occurred uniquely within one treatment (unshared VENN), or were differentially activated by two or more of the treatments (intersecting VENN). For clarity, VENN treatments have been grouped into (i) uncoated $\mathrm{ZnO}$ nanoparticles or (ii) coated $\mathrm{ZnO}$ nanoparticles, both against an ionic zinc treatment ( $\mathrm{ZnSO}{ }_{4}$ ).

the assay under the experimental conditions used here. Nevertheless, the strong activation of c-JUN and p38, combined with the statistically significant increase in the JUN, FOS, and GADD45 transcripts (data not shown), the last of which encodes a positive upstream regulator of p38 in response to cellular stress and growth arrest [37], provides a clear demonstration of the mobilization of hHSC stress responses when treated with uncoated $\mathrm{ZnO}$ nanoparticles. Treatment with these uncoated nanoparticles also elicited a negative influence on ERK and p70 phosphorylation, both of which were lower than control treatments after $2 \mathrm{~h}$, although phosphorylation of pERK increased significantly at $12 \mathrm{~h}$ for all five treatments (Figure 3, Supplementary Table S1). Both of these proteins are involved in regulation of cell growth and survival $[38,39]$, in addition to other cellular activities, and their de-phosphorylation here, in the context of the sharp decline at $24 \mathrm{~h}$ in metabolic activity in cells treated with either of the uncoated nanoparticles, but not HP1 or MAX (Figure 4, Supplementary Table S2), would be consistent with uncoated $\mathrm{ZnO}$ nanoparticle induction of a cell death, but a protective effect conferred by the addition of particle surface coatings.

Interestingly, the level of the AKT2 gene transcript (but not $A K T 1$ or $A K T 3$ ) was significantly higher (data not shown), and the phosphorylation of the AKT protein was strongly induced, in cells treated with Z-COTE or Nanosun, but not, or only weakly, by the coated nanoparticles (Figure 3). AKT phosphorylation regulates a number of pro-survival mechanisms within the cell through controlling anti-apoptotic mechanisms [40], and is typically considered to be a prosurvival response within the cell. AKT phosphorylation in cells treated with Z-COTE or Nanosun was accompanied by phosphorylation of the pro-apoptotic protein, BAD (Figure 3, Supplementary Table S1). Phosphorylation of BAD inhibits its pro-apoptotic activity by inhibiting the ability of $\mathrm{BAD}$ to form heterodimers with its anti-apoptotic binding partners BCL-2 and BCL- $\mathrm{X}_{\mathrm{L}}[39,41]$. The early activation of the antiapoptotic AKT, and inhibition of the pro-apoptotic BAD in cells treated with the uncoated nanoparticles, alongside the stress-associated pathways, may reflect an initial activation of pro-survival mechanisms within the cells that were ultimately overwhelmed by pro-apoptotic mechanisms, as indicated by elevated caspase activity (Figure 4).

A number of signalling molecules examined here showed no, or only minimal, modulation of phosphorylation. The level of phosphorylated $\mathrm{NF \kappa B}$, a pro-inflammatory, pro-cell survival transcription factor [42], was increased by treatment with the control agonist, TNFa, as expected (data not shown), but were only slightly elevated and then depressed by the nanoparticle treatments over the time-course examined (Figure 3, Supplementary Table S1). The NFKB1 gene transcript, encoding $\mathrm{NF \kappa B}$, was either down-regulated (by Nanosun), or not significantly modulated (all other treatments) (data not shown). Further, the NFKB1B gene transcript, encoding an NFKB inhibitor, was up-regulated in cells treated with Z-COTE or Nanosun, but not by the other treatments (data not shown). Together, these data, supported by the relatively weak activation of $\mathrm{NF \kappa B}$ in $\mathrm{ZnO}$-nanoparticle-treated olfactory cells [12], suggests that cellular stress responses to uncoated $\mathrm{ZnO}$ nanoparticles may not be primarily mediated by NFkB.

Phosphorylation of Chk1 and Chk2 in cells treated with either of the coated $\mathrm{ZnO}$ nanoparticles was generally lower than, or not different from, untreated cells. However, phosphorylation of the Chk2 was 
elevated in cells treated with either of the uncoated particles, with peaks occurring at 6-8 hours with maxima of $176 \%$ in the presence of Z-COTE and $158 \%$ in the presence of Nanosun. The Chk1 pathway is typically mobilised when DNA replication is impeded, whereas Chk2 is activated in the presence of breaks in double-stranded DNA [43]. Therefore, the apparent activation of Chk2 over Chk1 by treatment with uncoated $\mathrm{ZnO}$ nanoparticles may indicate the presence of strand breakage in DNA rather than DNA adducts. Interestingly, statistically-significant perturbations in the levels of transcripts encoding proteins involved in the response to repair damaged DNA tended to be negative, and present only in cells treated with Z-COTE and Nanosun. Furthermore, TP53, encoding the tumour suppressor protein $\mathrm{p} 53$, was also down-regulated in cells treated with Z-COTE and Nanosun, but not HP1 or MAX (data not shown).

The protective effect of surface coatings against $\mathrm{ZnO}$ nanoparticleinduced cellular injury was also evident at the transcriptional level. A snapshot of the transcriptome was taken at $24 \mathrm{~h}$ post-treatment, and was indicative of strong disregulation induced by Z-COTE $(10,037$ perturbed genes) and Nanosun (9,784 genes), but far less so by HP1 (80 genes), MAX (33 genes), and $\mathrm{ZnSO}_{4}$ (145 genes) (Figure 5A). Differentially-expressed transcripts were plotted in VENN diagrams. Nanosun and Z-COTE showed by far the greatest disruption to the transcriptome, much of which was shared between the two treatments, but not by any of the other treatments (Figure 5B), further demonstrating the protective effect of the particle surface coatings.

The comparative lack of a stress response in hHSCs treated with $\mathrm{ZnSO}_{4}$ is interesting given that the release of ionic zinc from $\mathrm{ZnO}$ nanoparticles has been postulated to drive their toxicity [6]. A consideration is that our use of a mass equivalent concentration of $\mathrm{ZnSO}_{4}$ to $\mathrm{ZnO}$ nanoparticles would result in a $\mathrm{Zn}^{2+}$ concentration from fully dissolved zinc sulphate that was $2.2 \mathrm{x}$ lower than that which would be produced from uncoated $\mathrm{ZnO}$ nanoparticles, assuming they were fully dissolved, which is unlikely. It is also important to note that ionic zinc is unlikely to be free, but rather will interact with components of the cell culture media. At concentrations greater than $5.5 \mu \mathrm{g} / \mathrm{mL} \mathrm{ZnO}$ nanoparticles, the solubilised zinc fraction equilibrates at approximately $67 \mu \mathrm{M}$, more than $99 \%$ of which is complexed with organic ligands in the media (DMEM supplemented with 10\% serum) [15]. Above this saturation limit, $\mathrm{ZnO}$ may produce zinc ions that may interact with cell culture components to precipitate as less-soluble zinc salts, such as zinc carbonate or zinc phosphate (depending on media components), or the $\mathrm{ZnO}$ nanoparticles may exist in a partially-dissolved form coated with zinc carbonate [15,44]. Therefore, at $30 \mu \mathrm{g} / \mathrm{mL}$ (the concentration used here), the concentration of free ionic zinc in cell culture medium treated with both $\mathrm{ZnO}$ nanoparticles and $\mathrm{ZnSO}_{4}$ was likely to have been similarly low. Further, the hHSCs were viable up to $277 \mu \mathrm{M}$ zinc in $\mathrm{ZnSO}_{4}$-treated cells, assuming full dissolution (Figure 1). These results add support to the contention that the total amount of ionic zinc in cell culture medium may be of less importance to $\mathrm{ZnO}$ cytotoxicity than intracellular, localised high concentrations following the uptake and intracellular dissolution of $\mathrm{ZnO}$ or $\mathrm{Zn}$-salt nanoparticles [15,44], although greater dissolution may be expected from $\mathrm{ZnO}$ than, for example, $\mathrm{ZnCO}_{3}$, based on their respective Ksp values in aqueous solution $\left(3.9 \times 10^{-10}\right.$ and $1.4 \times 10^{-11}$, respectively) [45].

The cellular stress and injury response observed here in response to treatment with uncoated $\mathrm{ZnO}$ nanoparticles is broadly consistent with those reported elsewhere using immortalised hepatic cell lines $[9,23,24,26]$, as well as in the livers of mice and rats treated in vivo $[17,18,20-22]$. Interestingly, however, the presence of a surface coating identical to HP1, which was protective here, was shown to exert minimal protective effect in the liver C3A cell line [23]. Furthermore, the results for HP1 reported here contrast with the HP1 fingerprint in olfactory cells, which was similar to those of Z-COTE and Nanosun, albeit mitigated and time-delayed [12]. We suggested there that the stability and/or coverage of HP1's coating may be inferior to that of MAX. While it is likely that the olfactory cells were simply more sensitive to $\mathrm{ZnO}$ nanoparticle treatment than the hepatic stellate cells used here, reflecting cell-line specific toxicity [46], we note that the experiments reported here were conducted prior to those in OsmondMcLeod by some months, raising the possibility that the trajectory of HP1 from benign to cytotoxic may reflect the impact of age and/or storage conditions on its surface coating, either by altering coat stability, or by elements adsorbed to the surface coating that may have altered the availability of HP1 to cells in vitro (unpublished data). A toxicological assessment of the impact of surface chemistry and toxicity of $\mathrm{HP} 1 \mathrm{ZnO}$ nanoparticles over time would be of interest to distinguish between the two possibilities, but was beyond the scope of this study.

In conclusion, the cellular profiles reported here showed that the surface-coated $\mathrm{ZnO}$ nanoparticles, HP1 and MAX, did not have a marked impact on cell signalling, function, viability, or transcriptional profile of human hepatic stellate cells. In contrast, the uncoated $\mathrm{ZnO}$ nanoparticles, Z-COTE and Nanosun, selectively activated pathways known to regulate cellular responses to abiotic stresses, and mechanisms known to control cell survival or apoptosis and senescence, reduce cell viability, and disregulate transcription. Further, these responses were generally not observed in cells exposed to ionic zinc alone. The presence of surface coatings, therefore, exerted a strongly protective effect against $\mathrm{ZnO}$ nanoparticle cytotoxicity. However, the influences of age and environmental exposure on the stability of surface coatings on particles, and on particle toxicity, over time should be investigated to further inform the use of surface coatings when applying a safetyby-design approach to the safe incorporation of $\mathrm{ZnO}$ nanoparticles in consumer products.

\section{Acknowledgement}

We thank: BASF and Micronisers Pty Ltd for their generous donations of the $\mathrm{ZnO}$ nanoparticles used in this study; Lynne Waddington, CSIRO, for size measurements by TEM; Gerry Triani, ANSTO, and Hong Yin, CSIRO, for surface area measurements; Victoria Coleman, National Measurement Institute of Australia, for DCS measurements; Ken Donaldson's laboratory (Edinburgh University) for use of their EPR instrument and reagents; and Glenn Osmond-McLeod and Julie Osmond for assistance with analysis and visualisation of microarray datasets.

This work was funded by the CSIRO Animal, Food and Health Sciences, the CSIRO Advanced Materials Transformational Capabilities Platform, and the CSIRO Future Manufacturing Flagship.

\section{References}

1. Osmond MJ, McCall MJ (2010) Zinc oxide nanoparticles in modern sunscreens: an analysis of potential exposure and hazard. Nanotoxicology 4: 15-41.

2. Xiong HM (2013) ZnO nanoparticles applied to bioimaging and drug delivery. Adv Mater 25: 5329-5335.

3. Chandra S, Barick KC, Bahadur D (2011) Oxide and hybrid nanostructures for therapeutic applications. Adv Drug Deliv Rev 63: 1267-1281.

4. Dastjerdi R, Montazer M (2010) A review on the application of inorganic nanostructured materials in the modification of textiles: focus on anti-microbial properties. Colloids Surf B Biointerfaces 79: 5-18.

5. Wang H, Du LJ, Song ZM, Chen XX (2013) Progress in the characterization and safety evaluation of engineered inorganic nanomaterials in food. Nanomedicine (Lond) 8: 2007-2025.

6. Vandebriel RJ, De Jong WH (2012) A review of mammalian toxicity of ZnO nanoparticles. Nanotechnol Sci Appl 5: 61-71. 
Citation: Osmond-McLeod MJ, Oytam Y, Osmond RIW, Sobhanmanesh F, McCall MJ (2014) Surface Coatings Protect against the In vitro Toxicity of Zinc Oxide Nanoparticles in Human Hepatic Stellate Cells. J Nanomed Nanotechnol 5: 232. doi: 10.4172/2157-7439.1000232

7. Moos PJ, Chung K, Woessner D, Honeggar M, Cutler NS, et al. (2010) ZnO particulate matter requires cell contact for toxicity in human colon cancer cells. Chem Res Toxicol 23: 733-739.

8. Poynton HC, Lazorchak JM, Impellitteri CA, Smith ME, Rogers K, et al. (2011) Differential gene expression in Daphnia magna suggests distinct modes of action and bioavailability for $\mathrm{ZnO}$ nanoparticles and $\mathrm{Zn}$ ions. Environ Sci Technol 45: 762-768.

9. Sharma V, Anderson D, Dhawan A (2012) Zinc oxide nanoparticles induce oxidative DNA damage and ROS-triggered mitochondria mediated apoptosis in human liver cells (HepG2). Apoptosis 17: 852-870.

10. Xia T, Kovochich M, Liong M, Mädler L, Gilbert B, et al. (2008) Comparison of the mechanism of toxicity of zinc oxide and cerium oxide nanoparticles based on dissolution and oxidative stress properties. ACS Nano 2: 2121-2134.

11. Deng X, Luan Q, Chen W, Wang Y, Wu M, et al. (2009) Nanosized zinc oxide particles induce neural stem cell apoptosis. Nanotechnology 20: 115101

12. Osmond-McLeod M, Osmond R, Oytam Y, McCall JM, Feltis B, et al. (2013) Surface coatings of $\mathrm{ZnO}$ nanoparticles mitigate differentially a host of transcriptional, protein and signalling responses in primary human olfactory cells. Part Fibre Toxicol 10: 54.

13. Yin H, Casey PS, McCall MJ, Fenech M (2010) Effects of surface chemistry on cytotoxicity, genotoxicity, and the generation of reactive oxygen species induced by ZnO nanoparticles. Langmuir 26: 15399-15408.

14. Yin $\mathrm{H}$, Casey PS, McCall MJ (2010) Surface modifications of $\mathrm{ZnO}$ nanoparticles and their cytotoxicity. J Nanosci Nanotechnol 10: 7565-7570.

15. Mu Q, David CA, Galceran J, Rey-Castro C, Krzemiaski L, et al. (2014) Systematic investigation of the physicochemical factors that contribute to the toxicity of ZnO nanoparticles. Chem Res Toxicol 27: 558-567.

16. Osmond-McLeod MJ, Oytam Y, Kirby JK, Gomez-Fernandez L, Baxter B, et al. (2014) Dermal absorption and short-term biological impact in hairless mice from sunscreens containing zinc oxide nano- or larger particles. Nanotoxicology 8. $72-84$

17. $\mathrm{Li} \mathrm{CH}$, Shen CC, Cheng YW, Huang SH, Wu CC, et al. (2012) Organ biodistribution, clearance, and genotoxicity of orally administered zinc oxide nanoparticles in mice. Nanotoxicology 6: 746-756.

18. Esmaeillou M, Moharamnejad M, Hsankhani R, Tehrani AA, Maadi H (2013) Toxicity of $\mathrm{ZnO}$ nanoparticles in healthy adult mice. Environ Toxicol Pharmacol 35: 67-71.

19. Paek HJ, Lee YJ, Chung HE, Yoo NH, Lee JA, et al. (2013) Modulation of the pharmacokinetics of zinc oxide nanoparticles and their fates in vivo. Nanoscale 5: 11416-11427.

20. Shrivastava R, Raza S, Yadav A, Kushwaha P, Flora SJ (2014) Effects of subacute exposure to $\mathrm{TiO} 2, \mathrm{ZnO}$ and $\mathrm{Al} 2 \mathrm{O} 3$ nanoparticles on oxidative stress and histological changes in mouse liver and brain. Drug Chem Toxicol 37: 336-347.

21. Sharma V, Singh $P$, Pandey AK, Dhawan $A$ (2012) Induction of oxidative stress DNA damage and apoptosis in mouse liver after sub-acute oral exposure to zinc oxide nanoparticles. Mutat Res 745: 84-91.

22. Wang L, Wang L, Ding W, Zhang F (2010) Acute toxicity of ferric oxide and zinc oxide nanoparticles in rats. J Nanosci Nanotechnol 10: 8617-8624.

23. Kermanizadeh A, Pojana G, Gaiser BK, Birkedal R, Bilanicová D, et al. (2013) In vitro assessment of engineered nanomaterials using a hepatocyte cell line: cytotoxicity, pro-inflammatory cytokines and functional markers. Nanotoxicology 7: 301-313.

24. Kermanizadeh A, Gaiser BK, Hutchison GR, Stone V (2012) An in vitro live model--assessing oxidative stress and genotoxicity following exposure of hepatocytes to a panel of engineered nanomaterials. Part Fibre Toxicol 9: 28.

25. Sharma V, Anderson D, Dhawan A (2011) Zinc oxide nanoparticles induce oxidative stress and genotoxicity in human liver cells (HepG2). J Biomed Nanotechnol 7: 98-99.

26. Wahab R, Siddiqui MA, Saquib Q, Dwivedi S, Ahmad J, et al. (2014) ZnO nanoparticles induced oxidative stress and apoptosis in HepG2 and MCF-7 cancer cells and their antibacterial activity. Colloids Surf B Biointerfaces 117 267-276

27. Kim AR, Ahmed FR, Jung GY, Cho SW, Kim DI, et al. (2013) Hepatocyte cytotoxicity evaluation with zinc oxide nanoparticles. J Biomed Nanotechnol 9: 926-929.
28. Filippi C, Pryde A, Cowan P, Lee T, Hayes P et al. (2014) Toxicology of ZnO and $\mathrm{TiO} 2$ nanoparticles on hepatocytes: Impact on metabolism and bioenergetics. Nanotoxicology.

29. Elpek GÖ (2014) Cellular and molecular mechanisms in the pathogenesis of liver fibrosis: An update. World J Gastroenterol 20: 7260-7276.

30. Friedman SL (2008) Hepatic stellate cells: protean, multifunctional, and enigmatic cells of the liver. Physiol Rev 88: 125-172.

31. Brunauer S, Emmett PH, Teller E (1938) Adsorption of gases in multimolecular layers. J Am Chem Soc 60: 309-319.

32. Brewer SH, Glomm WR, Johnson MC, Knag MK, Franzen S (2005) Probing BSA binding to citrate-coated gold nanoparticles and surfaces. Langmuir 21 9303-9307.

33. Leppä S, Bohmann D (1999) Diverse functions of JNK signaling and c-Jun in stress response and apoptosis. Oncogene 18: 6158-6162.

34. Coulthard LR, White DE, Jones DL, McDermott MF, Burchill SA (2009) p38(MAPK): stress responses from molecular mechanisms to therapeutics. Trends Mol Med 15: 369-379.

35. Maruyama J, Naguro I, Takeda K, Ichijo H (2009) Stress-activated MAP kinase cascades in cellular senescence. Curr Med Chem 16: 1229-1235.

36. Jochum W, Passegué E, Wagner EF (2001) AP-1 in mouse development and tumorigenesis. Oncogene 20: 2401-2412.

37. Johnen H, Salvador J (2009) The role of Gadd45a in suppression of autoimmunity. Mol cell Pharmacol 1: 290-298.

38. Raman M, Chen W, Cobb MH (2007) Differential regulation and properties of MAPKs. Oncogene 26: 3100-3112.

39. Harada H, Andersen JS, Mann M, Terada N, Korsmeyer SJ (2001) p70S6 kinase signals cell survival as well as growth, inactivating the pro-apoptotic molecule BAD. Proc Natl Acad Sci U S A 98: 9666-9670.

40. Stiles BL (2009) PI-3-K and AKT: Onto the mitochondria. Adv Drug Deliv Rev 61: $1276-1282$

41. Zha J, Harada H, Osipov K, Jockel J, Waksman G, et al. (1997) BH3 domain of $\mathrm{BAD}$ is required for heterodimerization with $\mathrm{BCL}-\mathrm{XL}$ and pro-apoptotic activity. J Biol Chem 272: 24101-24104.

42. Pereira SG, Oakley F (2008) Nuclear factor-kappaB1: regulation and function Int J Biochem Cell Biol 40: 1425-1430.

43. Smith J, Tho LM, Xu N, Gillespie DA (2010) The ATM-Chk2 and ATR-Chk1 pathways in DNA damage signaling and cancer. Adv Cancer Res 108: 73-112.

44. Turney TW, Duriska MB, Jayaratne V, Elbaz A, O'Keefe SJ, et al. (2012) Formation of zinc-containing nanoparticles from $Z n \hat{A}^{2} \hat{a}^{0}$ ions in cell culture media: implications for the nanotoxicology of ZnO. Chem Res Toxicol 25: 2057 2066.

45. http://www.saltlakemetals.com/SolubilityProducts.htm

46. Fröhlich E, Meindl C, Roblegg E, Griesbacher A, Pieber TR (2012) Cytotoxity of nanoparticles is influenced by size, proliferation and embryonic origin of the cells used for testing. Nanotoxicology 6: 424-439. 